\title{
Long-term efficacy of pulmonary rehabilitation with home-based or low frequent maintenance programs in patients with chronic obstructive pulmonary disease: a meta-analysis
}

\author{
Soh Imamura ${ }^{1,2}$, Takeshi Inagaki ${ }^{3}$, Jiro Terada ${ }^{1}$, Kengo Nagashima ${ }^{4}$, Hideki Katsura ${ }^{5}$, Koichiro Tatsumi ${ }^{1}$ \\ ${ }^{1}$ Department of Respirology, Graduate School of Medicine, Chiba University, Chiba, Japan; ${ }^{2}$ Division of Rehabilitation, Tokyo Women's Medical \\ University Yachiyo Medical Center, Chiba, Japan; ${ }^{3}$ Division of Rehabilitation, Chiba University Hospital, Chiba, Japan; ${ }^{4}$ Research Center for \\ Medical and Health Data Science, The Institute of Statistical Mathematics, Tokyo, Japan; ${ }^{5}$ Division of Respiratory Medicine, Tokyo Women's \\ Medical University Yachiyo Medical Center, Chiba, Japan \\ Contributions: (I) Conception and design: S Imamura, T Inagaki, J Terada, K Tatsumi; (II) Administrative support: J Terada, H Katsura, K Tatsumi; \\ (III) Provision of study materials or patients: S Imamura, T Inagaki; (IV) Collection and assembly of data: S Imamura, T Inagaki, J Terada; (V) Data \\ analysis and interruption: S Imamura, T Inagaki, J Terada, K Nagashima; (VI) Manuscript writing: All authors; (VII) Final approval of manuscript: \\ All authors. \\ Correspondence to: Jiro Terada. Department of Respirology, Graduate School of Medicine, Chiba University, 1-8-1 Inohana Chuo-ku, Chiba 260- \\ 8670, Japan. Email: jirotera@chiba-u.jp.
}

Background: The short-term efficacy of pulmonary rehabilitation (PR) in patients with chronic obstructive pulmonary disease (COPD) has been established. Although continuous follow-up and sustained exercise training is important to maintain the effects, the long-term efficacy of PR without frequent supervised training remains unclear. The aim of this meta-analysis was to investigate the long-term efficacy of PR with home-based or low frequent maintenance program on exercise capacity and health related quality of life (HRQOL) in patients with COPD.

Methods: We identified randomized controlled trials (RCTs) comparing long-term efficacy of PR with home-based or low frequent maintenance and no maintenance program from PubMed and the Cochrane Library. Primary outcomes were exercise capacity [6-minute walking distance (6MWD), incremental shuttle walking test (ISWT)] and HRQOL [St. George's Respiratory Questionnaire (SGRQ)]. Outcomes were combined using a random-effects model. This study is registered with PROSPERO, number CRD42019109718.

Results: Seven RCTs with a total of 492 patients with COPD met the inclusion criteria. PR with maintenance significantly improved 6MWD [mean difference (MD) 27.00; 95\% CI: 1.04-52.96; P=0.01] and ISWT (MD 44.48; 95\% CI: 30.70-58.25; $\mathrm{P}<0.01$ ), however no statistical evidence of improvement in HRQOL (MD -1.32; $95 \% \mathrm{CI}:-7.71$ to $5.08, \mathrm{P}=0.69$ ) was observed.

Conclusions: PR with maintenance programs appears to be more effective than without maintenance for preserving exercise capacity in the long-term in patients with COPD. No long-term efficacy on HRQOL were noted. To maintain the efficacy of PR on exercise capacity and HRQOL over a long duration, it might be necessary to reexamine the contents and frequency of maintenance programs.

Keywords: Chronic obstructive pulmonary disease (COPD); pulmonary rehabilitation (PR); long-term efficacy; maintenance; meta-analysis

Submitted Dec 04, 2019. Accepted for publication Jun 30, 2020.

doi: 10.21037/apm-19-581

View this article at: http://dx.doi.org/10.21037/apm-19-581 


\section{Introduction}

Chronic obstructive pulmonary disease (COPD) is the fourth leading cause of mortality in the world (1), which causes dyspnea of exertion (DOE), decreased physical activity, and muscle atrophy, leading to increased shortness of breath. Due to the irreversible state of the disease, patients with COPD have the potential to fall into a vicious downward spiral in which their physical function deteriorates. Pulmonary rehabilitation (PR) is recommended for patients with COPD as a valid strategy to interrupt this downward spiral and to prevent physical deconditioning (2). Regarding the PR setting, an outpatient protocol of PR for 6-12 weeks at least twice weekly, including breathing techniques, muscle strength training, aerobic training, self-management education, nutritional support, and psychosocial support has frequently been adopted (3). The efficacy of PR has frequently been reported as improving DOE, exercise capacity, physical activity, and healthrelated quality of life (HRQOL) $(2,4)$. To date, PR for patients with COPD has shown strong evidence for improving shortness of breath, exercise capacity, HRQOL, anxiety, and depression, and for decreasing the number of hospitalizations and admission days (3). However, previous studies reported that the improvements made during PR return to pre intervention levels at 12 to 24 months (5-7), even after the short-term efficacy of PR are observed.

Although continuous follow-up, such as sustained exercise training after the initial $\mathrm{PR}$ (PR with maintenance) is important to maintain the efficacy (8), maintenance length and setting tend to vary across maintenance programs (e.g., telephone (9), outpatient visit (10), and home visit (11). Beauchamp et al. (12) have reported that supervised exercise training after the initial PR appears to be more effective for maintaining exercise capacity up to 6 months, but not in the long term. They have also reported that HRQOL was not much maintained (12). On the other hand, given that continuation of supervised exercise training as maintenance is often difficult due to a lack of manpower and distance from the patient's home, home-based maintenance or infrequent follow-up should also be implemented.

The aim of this meta-analysis was to investigate the long-term efficacy of PR with maintenance, including home-based programs or infrequent follow-up on exercise capacity and HRQOL in patients with COPD. We present the following article in accordance with the PRISMA Reporting Checklist (available at http://dx.doi. org/10.21037/apm-19-581).

\section{Methods}

The meta-analysis protocol for the present study was registered in PROSPERO (International Prospective Register of Systematic Reviews; Registration ID: CRD42019109718; website: http://www.crd.york.ac.uk/PROSPERO/).

\section{Search strategy}

An extensive literature search of electronic databases was conducted to identify relevant randomized controlled trials (RCTs) between January 1995 and January 2019. The databases searched were PubMed and the Cochrane Library (Cochrane Central Register of Controlled Trials). Search terms and keywords were structured around the population (e.g., "COPD OR obstructive OR lung disease") and intervention (e.g., "rehabilitation OR physiotherapy OR physical therapy OR exercise OR training”).

\section{Study selection}

One author (S Imamura) performed the first-line comprehensive literature search and removal of duplicates. Subsequently, 2 authors (S Imamura, T Inagaki) independently screened the study titles and abstracts for potential relevance. These authors assessed the full text of articles to decide on inclusion. Any disagreement between authors was resolved by discussion. If necessary, a third author participated in the discussion to resolve the disagreement.

\section{Selection criteria}

\section{Population}

Patients with a confirmed diagnosis of COPD (mild to very severe) according to the Global Initiative for Chronic Obstructive Lung Diseases (GOLD) guidelines (13).

\section{Intervention}

The intervention was PR with maintenance programs. PR was defined as implementing a supervised exercise training program at least twice weekly for 6-12 weeks, with or without any form of education and/or psychological support. Maintenance programs were defined as followed up by telephone, outpatient visit, or home visit for maintaining the efficacy of PR at a certain frequency until 12 months after PR termination. To reveal the efficacy of PR with home-based or low frequency supervised maintenance 
programs, we excluded the study in which the frequency of maintenance programs was same as that of PR. We defined "low frequency" as frequency less than the frequency of implemented in-hospital PR.

\section{Comparison}

The comparator was any concurrent control group who had no maintenance program, with or without PR. We did not ask whether studies had PR, because we wanted to examine the long-term efficacy of continued follow-up by PR with maintenance programs.

\section{Outcome}

We considered exercise capacity and HRQOL. Exercise capacity was defined according to the results of a 6-minute walking distance (6MWD) (14) and an incremental shuttle walking test (ISWT) (15). HRQOL was measured using St. George's Respiratory Questionnaire (SGRQ) (16).

\section{Data extraction}

All citations and abstracts were downloaded to EndNote for review. Two authors (S Imamura, T Inagaki) extracted data using a standard data extraction form. Data included (I) general information: title, first author's name, year of publication; (II) general participant information: study population, sample size, interventions; (III) outcomes: 6MWD, ISWT, and SGRQ. These data were extracted from the original reports and entered into a spreadsheet.

\section{Risk of bias assessment}

Two authors (S Imamura and T Inagaki) independently assessed the risk of bias for included studies using the Cochrane risk of bias tool (17). The study quality assessment included random sequence generation, allocation concealment, selective reporting, blinding of participants and personnel, blinding of outcome assessment, incomplete outcome data, and other biases.

\section{Statistical analysis}

Review Manager version 5.3 was used to test the heterogeneity of the included studies and to conduct a meta-analysis for outcome measures. Throughout the analysis, we used mean differences (MD). The MD was combined according to a random-effects model using the DerSimonian-Laird method. MD and standard error (SE) were calculated for continuous outcomes using generic inverse variance. Heterogeneity across studies was estimated based on the $\mathrm{I}^{2}$ index. We considered the significant heterogeneity as $\geq 50 \%$ (17). We used, when possible, Egger's test to assess small study effects and publication bias.

\section{Results}

The latest research identified 11,363 articles. After the removal of duplicates, screening, and assessing eligibility, 7 articles remained and were included in the meta-analysis (Figure 1).

\section{Characteristics of the included studies}

Characteristics of the 7 studies are shown in Table 1. A total of 492 patients were included in these studies, and the overall intervention group consisted of 259 patients. All stages of COPD severity were represented across the included studies.

Three studies $(11,18,19)$ randomized patients to either a control group (usual care) or maintenance programs following PR. The other 4 studies $(9,10,20,21)$ randomized patients before PR. Two studies $(9,21)$ had the same component of PR in both groups. PR was not performed in the control group in the other 2 studies $(10,20)$.

The duration of PR was 6-12 weeks, and supervised exercise training frequency was at least twice weekly. In addition, almost all participants in the intervention group were instructed to implement home exercise during PR. All maintenance programs lasted between 12 months and 36 months except for Steele et al. (11), who provided a program for 12 weeks, but with 12 -month observation periods, following the completion of a supervised PR program. Maintenance programs were comprised of a telephone, outpatient visit, or home visit, with frequencies ranging from 1 session per week to 1 session per month. More details on interventions for all studies are shown in Table 1.

\section{Risk of bias}

Figure 2 provides an overview of the risk of bias. We judged 6 studies $(9-11,18,19,21)$ as having low risk of random sequence generation. Four studies $(9,10,18,21)$ allocated participants without knowing their allocation. In all studies, blinding of participants and personnel was high risk, given 


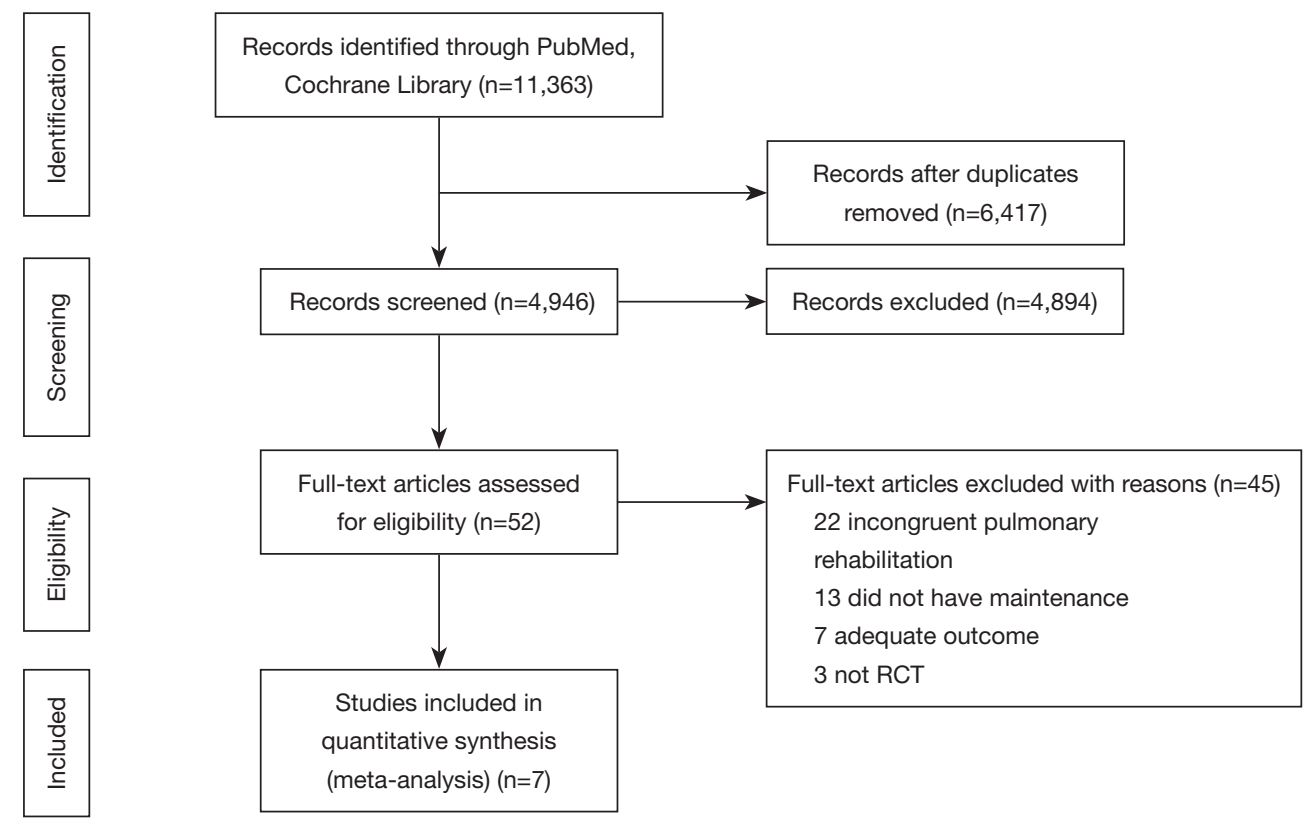

Figure 1 Flow diagram of study selection. PR, pulmonary rehabilitation; RCT, randomized controlled trial.

blinding of the rehabilitation intervention was impossible. Blinding of the outcome assessment was also not reported in all studies. Five studies $(9,10,18,19,21)$ found high risk of incomplete outcome data due to a per-protocol analysis and the inclusion of many patients who dropped out of the studies. Selective reporting was low risk for all studies.

\section{Efficacy of PR with maintenance on exercise capacity}

Six studies $(9-11,18,20,21)$ used exercise capacity as outcome. The 6MWD [5 studies $(9,11,18,20,21)]$ or ISWT [2 studies $(9,10)$ ] were used to assess exercise capacity. PR with maintenance significantly improved $6 \mathrm{MWD}$ (MD 27.00, 95\% CI: 1.04-52.96, $\mathrm{P}<0.05, \mathrm{I}^{2}=78 \%$ ) (Figure 3). Using ISWT, PR with maintenance significantly improved exercise capacity (MD 44.48, 95\% CI: 30.70-58.25, $\mathrm{P}<0.01$, $\mathrm{I}^{2}=0 \%$ ) (Figure 4). Egger's test for the $6 \mathrm{MWD}$ was not statistically significant.

\section{Efficacy of PR with maintenance on HRQOL}

Regarding HRQOL, the SGRQ total score was assessed in 4 studies $(9,10,19,20)$ (Figure $5 A$ ), and SGRQ subscores were assessed in 2 studies $(9,20)$ (Figure $5 B, C, D)$. The results of this meta-analysis suggested no statistically significant improvement of HRQOL using SGRQ in total score (MD $-1.32,95 \% \mathrm{CI}:-7.71$ to $5.08, \mathrm{P}=0.69, \mathrm{I}^{2}=64 \%$ ) and subscores (symptoms: MD 3.70, 95\% CI: -9.05 to 16.46, $\mathrm{P}=0.57, \mathrm{I}^{2}=81 \%$; activity: $\mathrm{MD}-1.04,95 \% \mathrm{CI}:-6.79$ to $4.72, \mathrm{P}=0.72, \mathrm{I}^{2}=48 \%$; and impact: $\mathrm{MD}-2.62,95 \% \mathrm{CI}$ : -13.71 to $\left.8.47, \mathrm{P}=0.64, \mathrm{I}^{2}=86 \%\right)$. Egger's test for SGRQ total score was not statistically significant.

\section{Discussion}

This meta-analysis investigated the long-term efficacy of PR with home-based or low frequent maintenance programs by reviewing $7 \mathrm{RCTs}$ and found that PR with these maintenance programs is superior to no maintenance for sustained benefit of exercise capacity in patients with COPD. However, the long-term efficacy on HRQOL were not observed according to this analysis.

To maintain the efficacy of PR on exercise capacity, exercise training is known to play a central role in PR, and continuation of exercise training is regarded as one of the most important factors (22). In the present metaanalysis, exercise training was continuously conducted at a maintenance phase in all studies, and 6 studies among them included aerobic training (9-11,18-20). In contrast, another study had implemented only muscle strength training, and did not show significant improvement in exercise capacity (21). Regarding the setting of maintenance programs, 4 studies $(10,18-20)$ had implemented supervised aerobic training at the maintenance phase, and their frequency was between 
Table 1 Characteristics of the included studies

\begin{tabular}{|c|c|c|c|c|}
\hline $\begin{array}{l}\text { Source, } \\
\text { country }\end{array}$ & Number of patients & PR program & Maintenance program & $\begin{array}{l}\text { Outcome } \\
\text { measure }\end{array}$ \\
\hline $\begin{array}{l}\text { Wootton } \\
2017(9) \\
\text { Australia }\end{array}$ & $\begin{array}{l}71 \text { patients (male: } \\
57 \% \text {; mean FEV1 of } \\
\text { pred.: } 43 \% \text {; mean } \\
\text { age: } 70 \text { years old); } \\
\text { Int: } 38 \text {; Con: } 33\end{array}$ & $\begin{array}{l}\text { Setting: outpatient; component: } \\
\text { AT (walking); duration: } 2 \\
\text { months; frequency: } 2-3 \text { times } \\
\text { weekly }\end{array}$ & $\begin{array}{l}\text { Setting: home, telephone; component: AT (walking), } \\
\text { pedometer feedback, progressive goal setting; } \\
\text { frequency (home): } 3 \text { times weekly; frequency } \\
\text { (telephone): every } 2 \text { weeks for the first } 3 \text { months, and } \\
\text { then one a month; follow-up: } 8,14 \text { months }\end{array}$ & $\begin{array}{l}\text { exercise } \\
\text { capacity: } \\
\text { 6MWD, } \\
\text { ISWT; } \\
\text { HRQOL: } \\
\text { SGRQ }\end{array}$ \\
\hline $\begin{array}{l}\text { Bestall } \\
2003(10) \\
\text { UK }\end{array}$ & $\begin{array}{l}47 \text { patients (male: no } \\
\text { description; mean } \\
\text { FEV1 of pred.: } 37 \% \text {; } \\
\text { mean age: } 69 \text { years } \\
\text { old); Int: } 26 \text {; Con: } 21\end{array}$ & $\begin{array}{l}\text { Setting: outpatient; component: } \\
\text { education, AT (walking or } \\
\text { cycling), MST (LE and UE); } \\
\text { duration: } 8 \text { weeks; frequency: } \\
\text { twice weekly }\end{array}$ & $\begin{array}{l}\text { Setting: outpatient; component: exercise and } \\
\text { discussion; frequency: once monthly; follow-up: } \\
6 \text { months, } 1 \text { year }\end{array}$ & $\begin{array}{l}\text { exercise } \\
\text { capacity: } \\
\text { ISWT; } \\
\text { HRQOL: } \\
\text { SGRQ }\end{array}$ \\
\hline $\begin{array}{l}\text { Guel } \\
2017(18), \\
\text { Spain }\end{array}$ & $\begin{array}{l}103 \text { patients (male: } \\
89 \% \text { mean } \mathrm{FEV} 1 \text { of } \\
\text { pred.: } 39 \% \text {; mean } \\
\text { age: } 64 \text { years old); } \\
\text { Int: } 53 \text {; Con: } 50\end{array}$ & $\begin{array}{l}\text { Setting: outpatient; } \\
\text { component: education, AT } \\
\text { (leg cycle ergometry), chest } \\
\text { physiotherapy, MST; duration: } \\
8 \text { weeks; frequency: } 3 \text { times } \\
\text { weekly }\end{array}$ & $\begin{array}{l}\text { Setting: home, outpatient, telephone; component: } \\
\text { chest physiotherapy, MST, AT (cycle ergometer); } \\
\text { frequency (home): } 3 \text { times weekly; frequency } \\
\text { (outpatient): once in the alternate week; frequency } \\
\text { (telephone): once every } 15 \text { days; follow-up: } 12,24 \text {, } \\
36 \text { months }\end{array}$ & $\begin{array}{l}\text { exercise } \\
\text { capacity: } \\
6 \mathrm{MWD}\end{array}$ \\
\hline $\begin{array}{l}\text { Linneberg } \\
2011 \text { (19), } \\
\text { Denmark }\end{array}$ & $\begin{array}{l}99 \text { patients (male: } \\
38 \% \text {; mean FEV1 of } \\
\text { pred.: } 42.2 \% \text {; mean } \\
\text { age: no description); } \\
\text { Int: } 49 \text {; Con: } 50\end{array}$ & $\begin{array}{l}\text { Setting: outpatient; component: } \\
\text { education, AT (walking or } \\
\text { cycle training), MST (LE, } \\
\text { UE, abdominal and thoracic } \\
\text { muscles); duration: } 7 \text { weeks; } \\
\text { frequency: twice weekly }\end{array}$ & $\begin{array}{l}\text { Setting: home, outpatient; component: supervised } \\
\text { exercise (similar to the PR), self-report written in diary; } \\
\text { frequency (home): every day; frequency (outpatient): } \\
\text { week } 9,11,13,18,26,52 \text {; follow-up: week } 13,26,52\end{array}$ & $\begin{array}{l}\text { HRQOL: } \\
\text { SGRQ; } \\
\text { (total score } \\
\text { only) }\end{array}$ \\
\hline $\begin{array}{l}\text { Roman } \\
2013(21) \\
\text { Spain }\end{array}$ & $\begin{array}{l}36 \text { patients (male: } \\
81 \% \text { mean FEV1 of } \\
\text { pred.: no description; } \\
\text { mean age: } 64 \text { years } \\
\text { old); Int: } 20 \text {; Con: } 16\end{array}$ & $\begin{array}{l}\text { Setting: outpatient; component: } \\
\text { education, respiratory } \\
\text { physiotherapy, MST (LE and } \\
\text { UE); duration: } 3 \text { months; } \\
\text { frequency: every day }\end{array}$ & $\begin{array}{l}\text { Setting: outpatient; component: MST and respiratory } \\
\text { physiotherapy; frequency: once weekly; follow-up: } \\
12 \text { months }\end{array}$ & $\begin{array}{l}\text { exercise } \\
\text { capacity: } \\
6 \mathrm{MWD}\end{array}$ \\
\hline
\end{tabular}

FEV1 of pred., forced expiratory volume in 1 second of predicted; 6MWD, 6-minute walking distance; ISWT, incremental shuttle walking test; SGRQ, St. George's Respiratory Questionnaire; AT, aerobic training; MST, muscle strength training; LE, lower extremity; UE, upper extremity; PR, pulmonary rehabilitation; Int, intervention group; Con, control group.

once weekly and once a month. In a recent study, Berry et al. (23) have demonstrated that supervised exercise training as a maintenance program 3 times per week for 12 weeks has benefits in maintaining exercise capacity; however, if the frequency of exercise training was relatively low, the efficacy of PR was not maintained $(5,23)$. On the other hand, Wijkstra et al. (24) have reported that a monthly supervised training group better maintained the effect of 


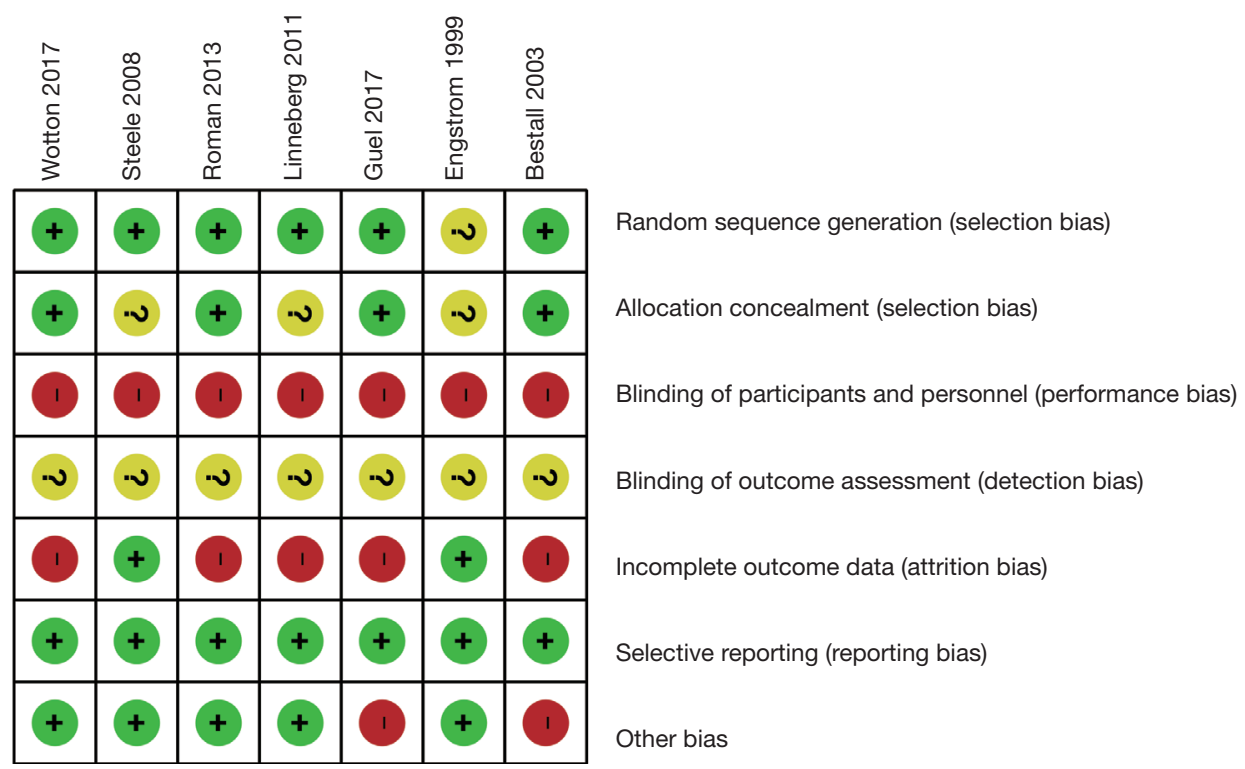

Figure 2 Risk of bias assessment.

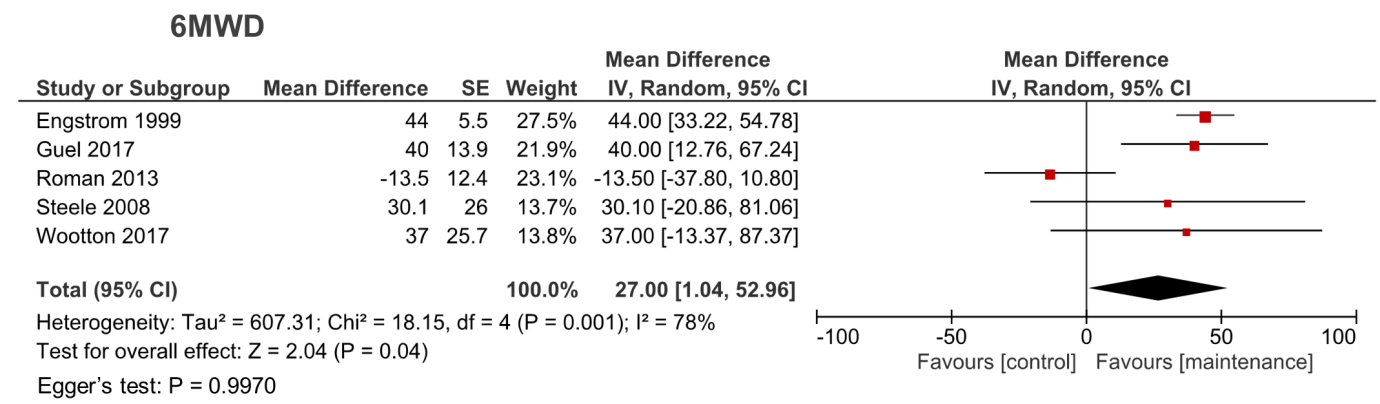

Figure 3 Effect of PR with maintenance compared with control group on 6MWD. PR, pulmonary rehabilitation; 6MWD, 6-minute walking distance; SE, standard error; IV, inverse variance; CI, confidence interval.

ISWT

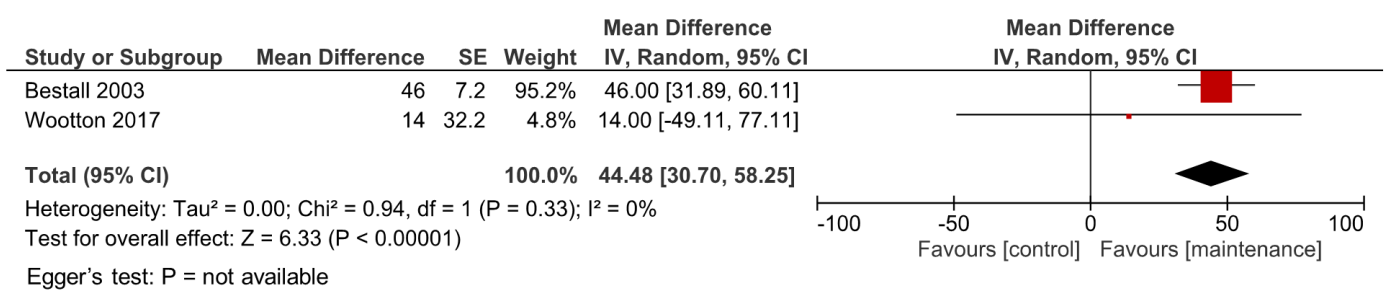

Figure 4 Effect of PR with maintenance compared with control group on ISWT. PR, pulmonary rehabilitation; ISWT, incremental shuttle walking test; SE, standard error; IV, inverse variance; CI, confidence interval. 
A SGRQ total score

\begin{tabular}{|c|c|c|c|c|c|c|c|}
\hline Study or Subgroup & Mean Difference & SE & Weight & $\begin{array}{l}\text { Mean Difference } \\
\text { IV, Random, } 95 \% \mathrm{Cl}\end{array}$ & \multicolumn{3}{|c|}{$\begin{array}{c}\text { Mean Difference } \\
\text { IV, Random, } 95 \% \mathrm{Cl}\end{array}$} \\
\hline Bestall 2003 & -4 & 4.6 & $23.7 \%$ & $-4.00[-13.02,5.02]$ & & $=-$ & - \\
\hline Engstrom 1999 & 3.1 & 0.9478 & $43.1 \%$ & $3.10[1.24,4.96]$ & & & - \\
\hline Linneberg 2011 & 3.4 & 12.4 & $6.0 \%$ & $3.40[-20.90,27.70]$ & & & \\
\hline Wootton 2017 & -7 & 3.9 & $27.3 \%$ & $-7.00[-14.64,0.64]$ & & & \\
\hline Total $(95 \% \mathrm{Cl})$ & & & $100.0 \%$ & $-1.32[-7.71,5.08]$ & & & \\
\hline \multicolumn{8}{|c|}{ 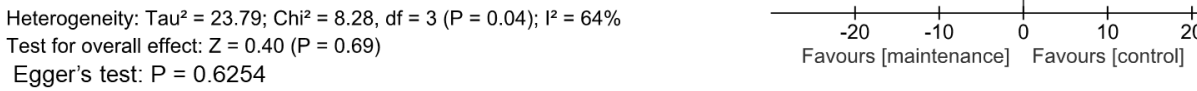 } \\
\hline
\end{tabular}

\section{B SGRQ symptoms}

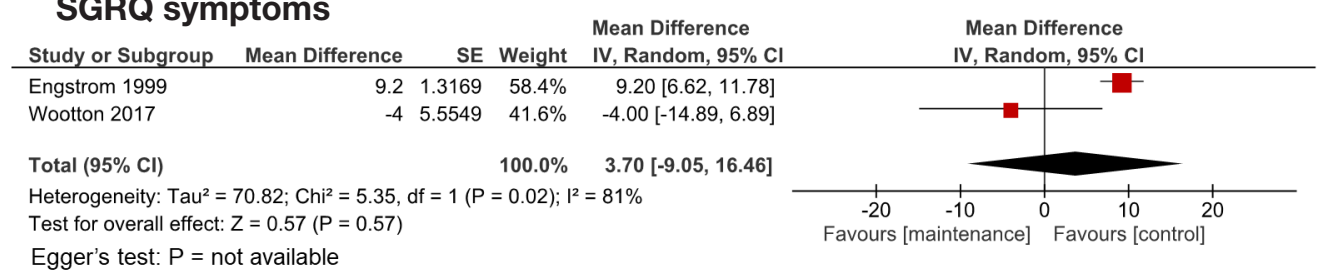
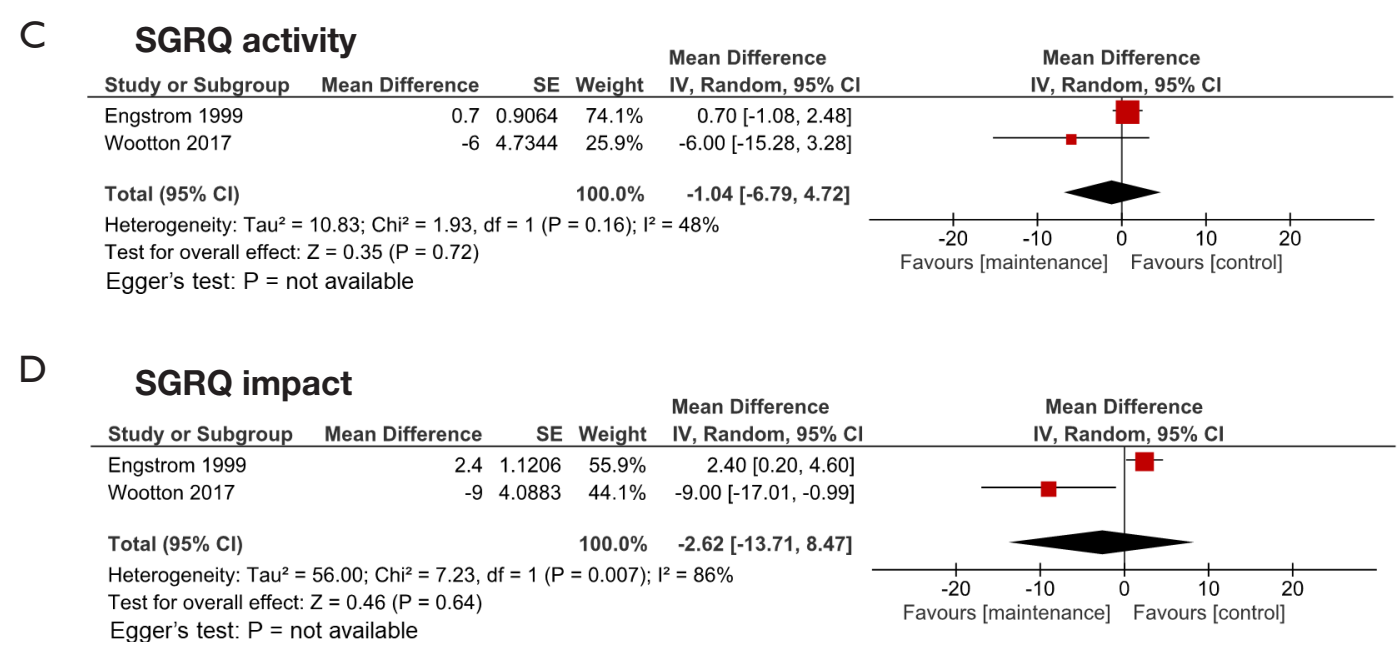

Figure 5 Effect of PR with maintenance compared with control group on SGRQ: (A) total score, (B) symptoms, (C) activity, and (D) impact. PR, pulmonary rehabilitation; SGRQ, St George's Respiratory Questionnaire; SE, standard error; IV, inverse variance; CI, confidence interval.

PR compared with a weekly group because the weekly group relied on supervised training and the monthly group performed more exercise training by themselves at home. Thus, to maintain the benefit of PR, sustained homebased exercise training might be more important than lowfrequency supervised training. Also in the present metaanalysis, 5 studies $(9,11,18-20)$ had implemented homebased unsupervised aerobic training at the maintenance phase, and their frequency was between 3 and 7 times per week. Although a systematic review of supervised exercise programs after PR in patients with COPD by Beauchamp et al. (12) has indicated that supervised training was important to maintain exercise capacity, almost all positive studies included in the present meta-analysis $(9,11,18,20)$ adopted frequent home-based exercise training with lowfrequency supervised training. In a previous study about the long-term benefit of home-based exercise training, continued exercise training after termination of PR was emphasized to maintain PR efficacy (25). This report has supported the results of the present meta-analysis. In summary, it is recommended to continue supervised exercise training at least 3 times per week if possible, and it is more important to plan the PR with a home-based exercise program which patients can continue in the maintenance phase. Thus, the action plan for the continuation of home-based unsupervised exercise training can lead to the 
integration of exercise training in daily life and physical activity, and will support long-term effectiveness.

Although the short-term efficacy of PR on HRQOL in patients with COPD have been clearly demonstrated (2), no long-term efficacy of HRQOL with a maintenance program were observed in the present meta-analysis. In another meta-analysis regarding the self-management interventions for patients with COPD, self-management, especially disease management, an action plan, nutritional support, and inhalation therapy were considered as quite important to improve HRQOL (26). Although 6 studies $(10,11,18-21)$ included in the present metaanalysis had implemented self-management education and showed improved HRQOL in the initial PR program, no education had been implemented at the maintenance phase. Romagnoli et al. (27) have reported that repeated $\mathrm{PR}$, including self-management education, was effective in HRQOL after 1 year of completing initial PR. This suggests that sustained self-management education in the maintenance phase is important to keep the efficacy of PR on HRQOL. On the other hand, behavioral change might be also a key component to maintaining HRQOL (22). The behavioral change, which includes incorporating multiple PR components (e.g., regular exercise training, the use of breathing techniques, the pace of movement, and energy conservation strategies) into the patient's lifestyle, seems important; continuing education to improve lifestyle throughout the maintenance phase could lead to maintaining the benefits of PR (4). In addition, self-efficacy appears to play a major role in explaining many health behaviors and is essential in planning PR (28). Higher levels of self-efficacy are associated with lower levels of breathlessness, anxiety, and depression (29). Therefore, it is difficult to maintain the long-term efficacy by continuation of exercise training alone, and it is necessary to intervene in self-efficacy and behavioral change, particularly using selfmanagement with a diary (30) and feedback from the daily steps (31). It appears possible to maintain the efficacy of PR on HRQOL by providing a program that can be continued at home and by adding self-management education and initiatives to improve self-efficacy. We perceive further approaches to maintain the benefits of PR could include, for example, community-based PR (32), tele-rehabilitation (33), and tele-coaching (34).

This meta-analysis was limited by the heterogeneity of the maintenance programs, time of the assessment, and frequency of interventions, given maintenance programs do not have enough consensus on the components, duration, and frequency. HRQOL was evaluated only by SGRQ because there were few studies with other outcomes (e.g., Chronic Respiratory Questionnaire, MOS Short-Form 36-Item Health Survey). Further research is needed to determine the long-term efficacy of PR with maintenance programs, including program factors, disease severity, and various outcomes (e.g., hospitalization days, anxiety, depression, shortness of breath, DOE, and physical activity).

\section{Conclusions}

This meta-analysis suggests that PR with maintenance programs confers long-term efficacy on exercise capacity in patients with COPD. However, no long-term efficacy on HRQOL were noted. To maintain the efficacy of PR on exercise capacity and HRQOL, it might be necessary to reexamine the contents and frequency of maintenance programs, such as the addition of self-management education, home-based and community-based unsupervised exercise training, and reimplementation of PR after a certain period.

\section{Acknowledgments}

We acknowledge the cooperation of authors (Allan Linneberg, Bonnie G. Steele, Maria-Rosa Guell, Sally L. Wootton, Miguel Roman, Carl-Peter Engstrom, and J. C. Bestall) of the included studies in this meta-analysis for providing data. The authors would like to thank Enago (www.enago.jp) for the English language review.

Funding: This work was supported, in part, by a research grant to the Intractable Respiratory Diseases and Pulmonary Hypertension Research Group, the Ministry of Health, Labor and Welfare, the Japan Agency for the Medical Research and Development (AMED; No. 6ek0109127h0002).

\section{Footnote}

Reporting Checklist: The authors have completed the PRISMA Reporting Checklist. Available at http://dx.doi. org/10.21037/apm-19-581.

Conflicts of Interest: All authors have completed the ICMJE uniform disclosure form (available at http://dx.doi. org/10.21037/apm-19-581). The authors have no conflicts of interest to declare. 
Ethical Statement: The authors are accountable for all aspects of the work in ensuring that questions related to the accuracy or integrity of any part of the work are appropriately investigated and resolved. The data for this study are from the database and therefore do not require ethical review.

Open Access Statement: This is an Open Access article distributed in accordance with the Creative Commons Attribution-NonCommercial-NoDerivs 4.0 International License (CC BY-NC-ND 4.0), which permits the noncommercial replication and distribution of the article with the strict proviso that no changes or edits are made and the original work is properly cited (including links to both the formal publication through the relevant DOI and the license). See: https://creativecommons.org/licenses/by-nc-nd/4.0/.

\section{References}

1. GBD 2015 Mortality and Causes of Death Collaborators. Global, regional, and national life expectancy, all-cause mortality, and cause-specific mortality for 249 causes of death, 1980-2015: a systematic analysis for the Global Burden of Disease Study 2015. Lancet 2016;388:1459-544.

2. McCarthy B, Casey D, Devane D, et al. Pulmonary rehabilitation for chronic obstructive pulmonary disease. Cochrane Database Syst Rev 2015;(2):CD003793.

3. Ries AL, Bauldoff GS, Carlin BW, et al. Pulmonary Rehabilitation: Joint ACCP/AACVPR Evidence-Based Clinical Practice Guidelines. Chest 2007;131:4S-42S.

4. Nici L, Donner C, Wouters E, et al. American Thoracic Society/European Respiratory Society statement on pulmonary rehabilitation. Am J Respir Crit Care Med 2006;173:1390-413.

5. Brooks D, Krip B, Mangovski-Alzamora S, et al. The effect of postrehabilitation programmes among individuals with chronic obstructive pulmonary disease. Eur Respir J 2002;20:20-9.

6. Foglio K, Bianchi L, Bruletti G, et al. Long-term effectiveness of pulmonary rehabilitation in patients with chronic airway obstruction. Eur Respir J 1999;13:125-32.

7. Ries AL, Kaplan RM, Limberg TM, et al. Effects of pulmonary rehabilitation on physiologic and psychosocial outcomes in patients with chronic obstructive pulmonary disease. Ann Intern Med 1995;122:823-32.

8. Ries AL, Kaplan RM, Myers R, et al. Maintenance after pulmonary rehabilitation in chronic lung disease: a randomized trial. Am J Respir Crit Care Med
2003;167:880-8.

9. Wootton SL, McKeough Z, Ng CLW, et al. Effect on health-related quality of life of ongoing feedback during a 12-month maintenance walking programme in patients with COPD: a randomized controlled trial. Respirology 2018;23:60-7.

10. Bestall JC, Paul EA, Garrod R, et al. Longitudinal trends in exercise capacity and health status after pulmonary rehabilitation in patients with COPD. Respir Med 2003;97:173-80.

11. Steele BG, Belza B, Cain KC, et al. A randomized clinical trial of an activity and exercise adherence intervention in chronic pulmonary disease. Arch Phys Med Rehabil 2008;89:404-12.

12. Beauchamp MK, Evans R, Janaudis-Ferreira T, et al. Systematic review of supervised exercise programs after pulmonary rehabilitation in individuals with COPD. Chest 2013;144:1124-33.

13. Vogelmeier CF, Criner GJ, Martinez FJ, et al. Global Strategy for the Diagnosis, Management, and Prevention of Chronic Obstructive Lung Disease 2017 Report: GOLD Executive Summary. Eur Respir J 2017;49:1700214.

14. ATS statement: guidelines for the six-minute walk test. Am J Respir Crit Care Med 2002;166:111-7.

15. Singh SJ, Morgan MD, Scott S, et al. Development of a shuttle walking test of disability in patients with chronic airways obstruction. Thorax 1992;47:1019-24.

16. Jones PW, Quirk FH, Baveystock CM, et al. A selfcomplete measure of health status for chronic airflow limitation. The St. George's Respiratory Questionnaire. Am Rev Respir Dis 1992;145:1321-7.

17. Higgins JPT, Green S. (eds). Cochrane Handbook for Systematic Reviews of Interventions Version 5.1.0 (updated March 2011). The Cochrane Collaboration, 2011.

18. Güell MR, Cejudo P, Ortega F, et al. Benefits of LongTerm Pulmonary Rehabilitation Maintenance Program in Patients with Severe Chronic Obstructive Pulmonary Disease. Three-Year Follow-up. Am J Respir Crit Care Med 2017;195:622-9.

19. Linneberg A, Rasmussen M, Buch TF, et al. A randomised study of the effects of supplemental exercise sessions after a 7-week chronic obstructive pulmonary disease rehabilitation program. Clin Respir J 2012;6:112-9.

20. Engstrom CP, Persson LO, Larsson S, et al. Longterm effects of a pulmonary rehabilitation programme in outpatients with chronic obstructive pulmonary disease: a randomized controlled study. Scand J Rehabil Med 1999;31:207-13. 
21. Roman M, Larraz C, Gomez A, et al. Efficacy of pulmonary rehabilitation in patients with moderate chronic obstructive pulmonary disease: a randomized controlled trial. BMC Fam Pract 2013;14:21.

22. Spruit MA, Singh SJ, Garvey C, et al. An official American Thoracic Society/European Respiratory Society statement: key concepts and advances in pulmonary rehabilitation. Am J Respir Crit Care Med 2013;188:e13-64.

23. Berry MJ, Rejeski WJ, Adair NE, et al. A randomized, controlled trial comparing long-term and short-term exercise in patients with chronic obstructive pulmonary disease. J Cardiopulm Rehabil 2003;23:60-8.

24. Wijkstra PJ, Ten Vergert EM, van Altena R, et al. Long term benefits of rehabilitation at home on quality of life and exercise tolerance in patients with chronic obstructive pulmonary disease. Thorax 1995;50:824-8.

25. Grosbois JM, Gicquello A, Langlois C, et al. Long-term evaluation of home-based pulmonary rehabilitation in patients with COPD. Int J Chron Obstruct Pulmon Dis 2015;10:2037-44.

26. Cannon D, Buys N, Sriram KB, et al. The effects of chronic obstructive pulmonary disease self-management interventions on improvement of quality of life in COPD patients: A meta-analysis. Respir Med 2016;121:81-90.

27. Romagnoli M, Dell'Orso D, Lorenzi C, et al. Repeated pulmonary rehabilitation in severe and disabled COPD patients. Respiration 2006;73:769-76.

28. Bourbeau J, Nault D, Dang-Tan T. Self-management and

Cite this article as: Imamura S, Inagaki T, Terada J, Nagashima K, Katsura H, Tatsumi K. Long-term efficacy of pulmonary rehabilitation with home-based or low frequent maintenance programs in patients with chronic obstructive pulmonary disease: a meta-analysis. Ann Palliat Med 2020;9(5):2606-2615. doi: 10.21037/apm-19-581 behaviour modification in COPD. Patient Educ Couns 2004;52:271-7.

29. Simpson E, Jones MC. An exploration of self-efficacy and self-management in COPD patients. Br J Nurs 2013;22:1105-9.

30. van Kruijssen V, van Staa A, Dwarswaard J, et al. Use of Online Self-Management Diaries in Asthma and COPD: A Qualitative Study of Subjects' and Professionals' Perceptions and Behaviors. Respir Care 2015;60:1146-56.

31. Varas AB, Cordoba S, Rodriguez-Andonaegui I, et al. Effectiveness of a community-based exercise training programme to increase physical activity level in patients with chronic obstructive pulmonary disease: A randomized controlled trial. Physiother Res Int 2018;23:e1740.

32. Waterhouse JC, Walters SJ, Oluboyede Y, et al. A randomised $2 \times 2$ trial of community versus hospital pulmonary rehabilitation, followed by telephone or conventional follow-up. Health Technol Assess 2010;14:iv, vii-xi, 1-140.

33. Vasilopoulou M, Papaioannou AI, Kaltsakas G, et al. Home-based maintenance tele-rehabilitation reduces the risk for acute exacerbations of COPD, hospitalisations and emergency department visits. Eur Respir J 2017;49:1602129.

34. Nguyen HQ, Gill DP, Wolpin S, et al. Pilot study of a cell phone-based exercise persistence intervention postrehabilitation for COPD. Int J Chron Obstruct Pulmon Dis 2009;4:301-13. 